\title{
Designing Brutal Multiplayer Video Games
}

\author{
Joe Marshall \\ School of Computer Science \\ University of Nottingham, UK \\ joe.marshall@nottingham.ac.uk
}

\author{
Conor Linehan \\ School of Applied Psychology \\ University College Cork, Ireland \\ conor.linehan@ucc.ie
}

\author{
Adrian Hazzard \\ School of Computer Science \\ University of Nottingham, UK \\ adrian.hazzard@nottingham.ac.uk
}

\begin{abstract}
Non-digital forms of play that allow players to direct brute force directly upon each other, such as martial arts, boxing and full contact team sports, are very popular. However, inter-player brutality has largely been unexplored as a feature of digital gaming. In this paper, we describe the design and study of 2 multi-player games that encourage players to use brute force directly against other players. Balance of Power is a tug-of-war style game implemented with Xbox Kinect, while Bundle is a playground-inspired chasing game implemented with smartphones. Two groups of five participants $(n=10)$ played both games while being filmed, and were subsequently interviewed. A thematic analysis identified five key components of the brutal multiplayer video game experience, which informs a set of seven design considerations. This work aims to inspire the design of engaging game experiences based on awareness and enjoyment of our own and others' physicality.
\end{abstract}

\section{Author Keywords}

Brutal; physical; games; game design.

\section{ACM Classification Keywords}

H.5.m. Information interfaces and presentation (e.g., HCI): Miscellaneous.

\section{INTRODUCTION}

The design of digital games rarely encourages physical contact between players. This is perhaps due to constraints inherent in the physical form of game input devices, such as game controllers and keyboards, which are designed to be used by individual players, require players to remain relatively still, and measure only the movement of hands and fingers. However, recent developments in mobile and ubiquitous computing technology, such as Microsoft Kinect and accelerometer-enabled smartphones allows for game input to be expressed through a much wider range of player

Permission to make digital or hard copies of all or part of this work for personal or classroom use is granted without fee provided that copies are not made or distributed for profit or commercial advantage and that copies bear this notice and the full citation on the first page. Copyrights for components of this work owned by others than the author(s) must be honored. Abstracting with credit is permitted. To copy otherwise, or republish, to post on servers or to redistribute to lists, requires prior specific permission and/or a fee. Request permissions from Permissions@acm.org

CHI'16, May 07 - 12, 2016, San Jose, CA, USA

Copyright is held by the owner/author(s). Publication rights licensed to ACM.

ACM 978-1-4503-3362-7/16/05 ..\$15.00

DOI: $\underline{\text { http://dx.doi.org/10.1145/2858036.2858080 }}$ movement and interaction.

The new design spaces opened by these technologies have to date been exploited primarily by; 1) commercial games, such as Wii Sports, that involve some movement but largely replicate the design of traditional sedentary video games, and 2) exertion games, that intend to gamify [29] physical exercise. Both of these game styles typically seek to minimize physical contact between players and either favour controlled and conservative levels of physical exertion, or at least mediate player brutality by only allowing players to have contact via a digital interface (e.g. [16]). A few games do exist which encourage players to directly physically interact with other players, such as B.U.T.T.O.N and Johann Sebastian Joust by Douglas Wilson and the Copenhagen Game Collective [32,33]. Even these games fall far short of asking players to engage in the types of brutal full contact interactions that are seen in martial arts.

Physical contact is however extremely common in nondigital games, from children's playground games such as British Bulldog and Red Rover [15], to full contact sports such as rugby, martial arts and ice hockey [26]. Physical contact with other players is not incidental in these games, it is a core reason why people enjoy playing them [26]. People enjoy trying to gain advantage over other players through pushing, pulling, grabbing, dodging and hitting.

The popularity of extreme physicality between players in non-digital gaming highlights a gaming aesthetic that has largely been overlooked by designers of digital games. This paper extends upon the findings of previous research on physical contact $[32,33]$ and mediated brute force $[13,16]$ games. Our intention with this paper is to understand better the opportunities and challenges in designing compelling digital games that require full force inter-player interaction. In the remaining sections of this paper we will first discuss previous research on physical interaction in game play; examining children's games, sports, exertion games and previous brute force games. We then discuss the design and implementation of 2 games, Balance of Power and Bundle, which have been designed specifically to explore brute force as a game aesthetic (and pushing, pulling, hitting and running as mechanics). We describe a user study carried out to understand players' subjective experience of playing those brutal games, before presenting a thematic analysis of video and interview data captured during the study. This data is used to inform design considerations for future brutal multiplayer digital games. 


\section{BACKGROUND}

To design brutal video games, we must first understand why people engage in vigorous physical play and what it is about brutal physical games that players find compelling.

\section{Physicality in games}

Games such as rugby, martial arts and ice hockey, which involve physical force between players, are popular among women, men and children both as spectator and participatory activities [8]. There is little research on what people enjoy about those games from a kinaesthetic, social or tactical perspective. Academic studies tend to examine violent sports with regard to cultural practices of spectators, societal views of players, sexism, effects of professionalism, and construction of self-identity [8,21]. Often studies pathologise cultures around violent sports, equating sport violence with violence in society. For example, [30] and [26] study hockey violence, but focus only on fighting, ignoring positive aspects of physical play. Few studies produce coherent accounts of the experience of playing violent games. However, useful insights may be drawn from two topics; study of children's physical play, and studies of motivation of violent sports players.

\section{Children's Physical Play}

Much work has been conducted understanding children's play, including a vigorous physical component. Pellegrini $\&$ Smith [22] describe how rough and tumble play, including wrestling, grappling, kicking and tumbling is a key part of childhood play. These games typically have loose and negotiable rules and winning conditions [3] (for example, there is great variation in how 'bases' function in the common playground game of 'tag'), and include core mechanics such as chasing, catching, grappling, and pinning players. Forceful physical contact between players is ever-present. Specific games include Tag, British Bulldog, Blindman's Buff and Cops and Robbers [23].

It has been argued that vigorous physical play serves both long-term developmental functions (cognition, emotional coding, fighting skills) plus more immediate functions (strength and endurance training, social dominance functions)[22]. However young players are not aware of these long-term benefits. In other words, children engage in vigorous physical play as it is inherently enjoyable [22].

\section{Violent sports}

The study of adult sports provides some insight on the components of vigorous physical play that people find so compelling. People choose freely to engage in brutal physical sports. Similarly with children's play, there seems to be some inherent enjoyment in the bodily experience of engaging in aggressive competition, hitting, and the finding of strength in the body. A recent study by Paul [21] characterizes female participants experiences of playing roller derby, mixed martial arts and rugby. Roller Derby players reported empowerment by the opportunity to hit and be hit, to feel bodily power and liberation, and mentioned the game as a great way to de-stress and gain a sense of release from everyday challenges. Rugby players expressed a love for the physical feeling of hitting, tackling, and overpowering an opponent, as well as the empowerment drawn from the ability to get back up after receiving a hit. Violence, aggression and pain are a key part of what Jirásek and Hurych describe as an authentic sporting experience [10], which Paul [21] suggests can help achieve bodily empowerment, confidence, and self-efficacy.

\section{Physicality in Digital games}

Vigorous physical play presents compelling design opportunities for video games. Indeed, commercial and research projects exist which use full body physical motion as a game input, which have potential to support vigorous or brutal physical play. For example, Wii Sports allows players to engage with bowling and baseball games through the stereotyped 'bowling' and 'batting' movements. However, the commercial games deployed for devices such as Nintendo Wii and Microsoft Kinect tend to closely resemble sedentary games in both the vigour of physical activity necessary to play, and the character of inter-player physical contact engendered (i.e., minimal contact, if any).

\section{Exertion Games}

Games where players must exert themselves to play are well established in research, with games controlled by jogging [18], cycling [27], swimming [5] and even based on how long a player can hold their own weight [19]. Commercial games have also begun to use sensing technology to promote exercise. For example, Zombies Run [1] is a GPS enabled audio story where players are chased by hordes of zombies, and must run to escape them.

While exertion games promote exercise and physical activity, they are largely non-contact experiences, and mostly do not involve large amounts of force. However, a few exertion games have specifically explored brute force and vigorous physical activity as a game aesthetic. For example, Grand Push Auto [13] challenges players to push an automobile for specified periods of time, requiring real brute force and making players push through significant levels of pain. Mueller et al. [17] describe a game where two players engage in a vigorous fight involving kicking and punching, but instead of attacking each other physically, each player attacks a soft game interface.

Mueller et al. [16], in some of the most relevant work for the current paper, were interested in designing brute force video games. They initially sought to understand the appeal of contact sports through an online survey of 24 participants. Findings suggest that brute force games can be described through the extent to which they include each of eight separate features; competitiveness, intensity, directness, injuries, social aspect, fearlessness, spectatorship and organizational. Physical games such as martial arts and rugby involve high levels of all of these features. Interestingly, however, existing exertion video games rarely score high on a majority of these features. For example, Mueller's work $[16,17]$ aims to moderate 
intensity, directness and injuries and promote fearlessness through removing inter-player contact.

\section{Digital Games with Player Contact}

There are some games that do encourage inter-player pushing, pulling and jostling. Two games by Copenhagen Game Collective [33] deliberately encourage physical contact: In Johann Sebastian Joust, players jostle controllers of other players whilst preventing their controller from moving. Party game B.U.T.T.O.N [32] gives instructions such as "the last person whose gamepad button is pushed wins" and encourages "brutally unfair tactics" such as pressing other players' buttons, or physically blocking players from following instructions. In Mueller et al.'s [16] terms, these games are physical, direct and competitive and support playful, and enjoyable experiences; however, much like exertion games, they come nowhere near the physical intensity, fearlessness and likelihood of injury involved in a game of rugby or a martial art.

\section{STUDYING BRUTAL GAMES}

In the next sections, we describe two games we designed deliberately to encourage the quality and intensity of interplayer brutal physical contact often seen in full contact physical games [21] but rarely seen in digital games. Both are designed to promote features of full contact sports [16]. We were also informed by existing guidelines for 'movement games' and 'body games' [9,12], in particular when considering the social aspects of our game designs. Studying participants' experiences with these games allows us to address our fundamental research question: How should we design good full contact digital games?

Our initial idea when designing these games was to build 'digital playground games'. From literature descriptions of playground games [23] and our own experience, we identified forceful physical contact as a key area in which playground and digital games typically differ. We refined our initial game designs through several prototypes, which were shaped through a combination of playtesting and practical constraints such as spaces we could find to run games, safety concerns \& equipment availability.

\section{GAME 1: BALANCE OF POWER}

Balance of Power (BoP) is a game for two teams with the same number of players on each team. It is designed to be played on an international standard squash court [34]. We chose a squash court because it is an easy to find space that is roughly consistent in setup, has minimal obstructions that might injure players, and is ideally sized for the sensing technology used (Figure 1 shows a diagram of the setup).

In BoP, the court is split down the centre line, with a large projection on the back wall of the court showing silhouettes of all the players, along with a see-saw style balance. The two teams of players each have ownership of one half of the court, which is shown by the red and green colouring of the silhouettes displayed on the projector screen (see Figure 2).

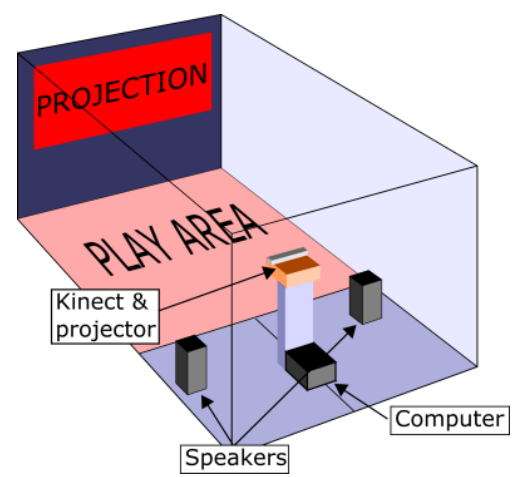

Figure 1. Balance of Power Squash court layout

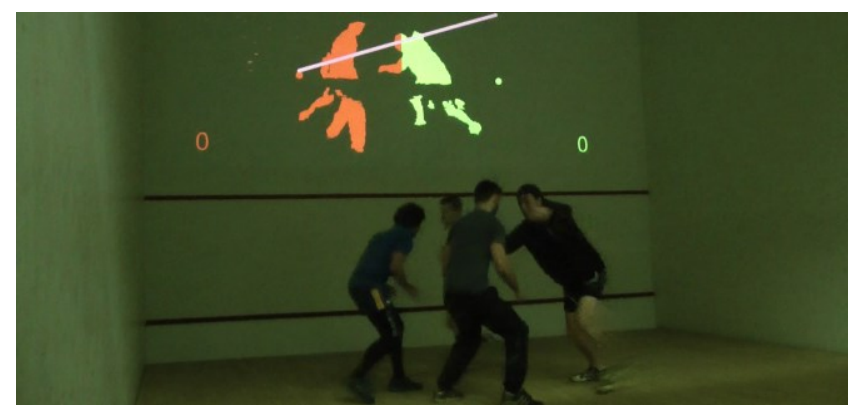

Figure 2. Players face off in Balance of Power.

Players must try and force the other team onto their side of the court. As players come over to one side, the balance tips towards that side. At random intervals of 10-30 seconds, a countdown of 5 seconds occurs. When the countdown ends, the team with the balance on their side scores a point; if the balance is in the middle, a 'Balance of Power' occurs, and no one scores. The first team to score 3 points wins. There is one final gameplay event, which occurs instead of a score countdown approximately $20 \%$ of the time, which is a 'swap sides'. When a swap sides occurs, the side of the court that players 'own' swaps over, and they must try and get the opposing players to their new side instead.

\section{Implementation}

BoP uses the 3D depth sensing capabilities of a Microsoft Kinect camera. The camera is placed in the centre of the court outside the play area which is in the front section of the court (Figure 1). Because the mechanic of the game is just about getting as many players as possible onto your side, it does not need to track player identity or posture. So, rather than individually tracking the players, it simply uses the Kinect depth detection to estimate the area of each side of the play space which is not part of the background. This simple tracking means that it is able to detect players even if they are touching other players, are upside down, being carried, are partially occluded or are otherwise in postures which the Kinect player tracking cannot sense. An audio track accompanied the game. This consisted of two layers of audio, a dance music track to set the mood, which sounded throughout, and prepared spoken cues, which 'refereed', or directed gameplay. This audio track was broadcast from a small PA system at the back of the court. 


\section{GAME 2: BUNDLE}

Balance of Power explores a relatively traditional form of brutal play between balanced opposing teams of players. This kind of play occurs in many sports such as wrestling and boxing, and is also common as a theme in computer fighting games. The Bundle Game is an attempt to explore a different form of brutal play, inspired by the playground 'bundle' or 'pile-on', common in the UK. In the traditional game, a person shouts 'bundle' and jumps on another, soon followed by all other players jumping on the pile. Bundle aims to take this highly unbalanced mode of physical play, and create a fair game based around it.

Bundle has no visual interface and relies purely on audio played on mobile phones held in the player's pockets. In testing, we also mirrored the audio to speakers in the room to help overcome background noise from air conditioning.

When Bundle begins, ominous horror film style cello music starts playing from all phones. After a few seconds, all phones say " $<$ Player name $>$ is it", and that player's phone starts emitting a loud beeping sound, which lasts for 3 seconds. After these 3 seconds, the phone emits a siren for 2 seconds. During these two seconds, the other players must try their hardest to stop that player from moving, whilst the player tries to evade them and keep running around. All players except the one who was 'it' receive points based on how well the 'it' player was caught. The game then goes back to horror film music for 10-15 seconds, giving the players a rest before a new player is chosen.

All players are made 'it' an equal number of times, but the ordering is randomized, meaning that in pauses between attacks, nobody knows who is going to be 'it' next, so players must balance being close to other players to catch them, and keeping their distance for escape attempts. This typically leads to uneasy circling as players vie for space and try to get into optimal position relative to other players. We also tested a second variation of the Bundle game in which rather than catch the player so that they stayed still, attackers gained points for moving the player, and the player who was attacked had to keep as still as possible.

\section{Implementation}

Bundle is implemented on a set of Android smartphones running on a local wifi network. The game runs on each phone, with one phone acting as the master device, controlling who is 'it' and when game actions happen. There is also a standalone listener client which allows audio from all phones to be transmitted over speakers by a laptop.

To detect how still a player is, or much they are moved by an attack, Bundle uses an accelerometer based algorithm. Because different devices (and even different phones across a single device family) have differing sensor noise levels or data rates, a custom filter algorithm is used to normalize across the phones. This first takes the raw accelerometer magnitude, median filters and high pass filters the data (both with 0.2 second time constants) to reduce sensor noise

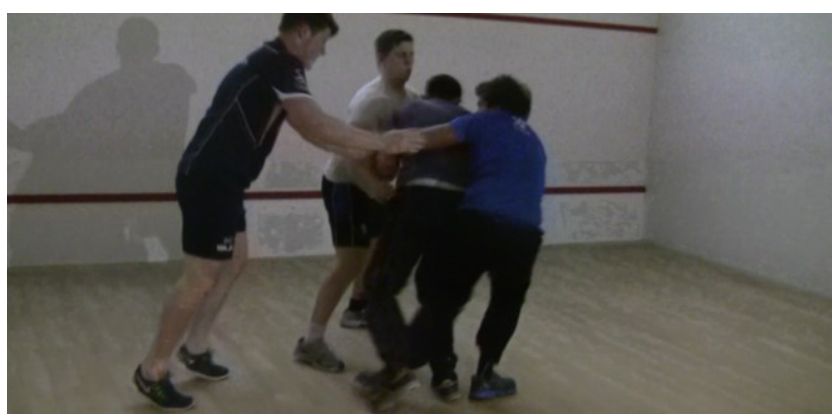

Figure 1. Attackers try to keep the 'it' player still in Bundle.

and gravity respectively. Finally the magnitude is normalized by dividing it by a device constant calculated by low pass filtering 15 seconds prior to measurement starting while players are typically at rest. This means that the game can be played with an arbitrary selection of Android devices without giving any one player an advantage.

\section{STUDY METHODOLOGY Participants}

It was not appropriate to recruit participants randomly from the general population. Rather, we selectively sampled appropriate groups. This was necessary because; 1) we are specifically interested in building games for people who already enjoy brute force physical activities, and 2) for health and safety reasons, and for the purposes of ethical approval, it was necessary to include in the study only people who had extensive previous experience and training in playing brutal games. Essentially, we wanted to recruit people who could play the games in a fully engaged manner without undue risk of physical injury. Advertisements were placed on the social media accounts of a number of local rugby clubs, and one such club volunteered to participate. Group 1 consisted of five male participants, all aged between 18 and 22, all current playing members of a highlevel university rugby club. Group 2 were recruited through advertisement in a university game design class. These five participants, also male and aged 18-22, all had significant previous experience in playing and enjoying rugby, but were not active members of a team at the time of the study.

\section{Ethical Approval}

Ethical approval was obtained from committees at the Universities of Nottingham and Lincoln. Beyond the typical concerns for informed consent and anonymity it was important to ensure that Health and Safety procedures were in place in case of injury occurring. Play sessions took place in a squash court in the University of Lincoln sports complex at times when First Aid trained instructors were present in the centre. All players were briefed in advance and wore appropriate clothing and footwear.

\section{Data Collection}

Data was collected in two sessions, one per group. Both games were designed with a "round" structure, where a round lasted 2-3 minutes. Each group played BoP first for 3 rounds, followed by 2 rounds of Bundle. In each round, 1 
player sat out, to maintain balanced teams, and to allow the most tired player to rest. In breaks between rounds, which typically lasted up to five minutes, researchers interviewed participants as a group about their experience, using a semi structured interview schedule. Interviews also continued for approximately 20 minutes after all rounds had finished. Participants were video recorded both playing the games and during interviews. Video data in this project is nonanonymised personal data, and is not publicly available. Anonymized transcripts and analysis spreadsheets are available to as supplementary material.

\section{Analysis}

Participant interviews were transcribed from video files and the data from both groups were combined into one spreadsheet ready for qualitative analysis. Units were defined as speaking turns, thus there was significant variance in the length of those units. In total, there were 771 units included in the analysis. An inductive thematic analysis was then conducted on the data set following the method outlined by Braun and Clarke [2]. This method was deemed appropriate, as the design of full contact digital games is an emerging and poorly understood topic, for which limited relevant theory currently exists. Two researchers independently read all units a number of times, and category codes were initially identified by each researcher, together with a description and examples of each code. Units could be labelled with up to three codes each. An online meeting was held in which the codes were discussed and refined, until agreement was reached on a total of 19 codes. The coding categories were then examined and cross-referenced with the data and further analyzed for overarching themes, which were identified and reviewed by both researchers. After interviews were analysed, we analysed gameplay videos. We found that the insights from the video analysis fitted into the categories already established from interview analysis, and required no new categories. For example in the interviews players discussed their opinions on screen feedback, and in the video we were able to see in more detail how players split their attention between on-screen and physical gameplay.

\section{RESULTS AND DISCUSSION}

Five overarching themes were identified in the data; Space, Technology, Game Design, Physical Awareness and Brutal Play. Each of these is discussed in turn below.

\section{T1: Space}

This theme describes participants' discussion of the physical space the game was played in. 59 of the total 771 units are characterized by this theme. Participants commented on the experience of playing highly physical games in a squash court that had hard concrete walls, hard wood floors and no padding. "Softer floor. It definitely needs mats I think," "softer walls maybe as well [rubs arms], laugh." However, there weren't any feelings of danger expressed over playing in that environment, "it wasn't too bad... I've just kind of got scuffed knees and things like that," "just makes it more fun," "the walls didn't

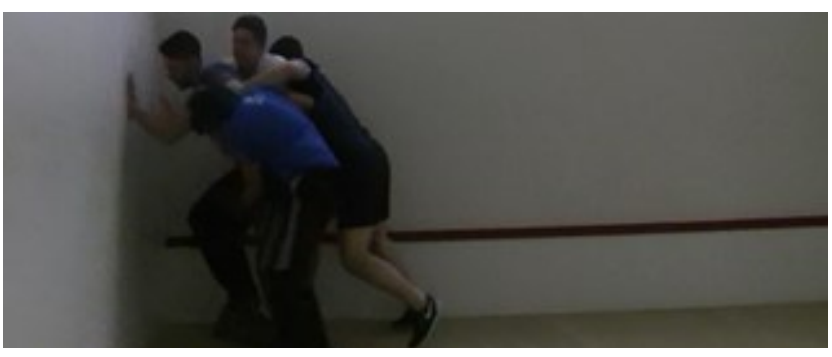

Figure 2. Players found it hard to escape the corner in Bundle

bother us... might bother some people". Indeed, it is possible that playing on softer surfaces may actually make games more dangerous through encouraging more violent play. Participants commented that the size of the squash courts was not ideal for the physical nature of the games, particularly in Bundle, where people could be manhandled into corners (Figure 4), "that game would be better with a bigger space," "three on one in this space is too much maybe." On further discussion, it emerged that a key drawback of the small space was that, "you can't like tackle people if you've got no room to accelerate," "in a small room, it's like restricted to like how good you are at accelerating." Thus, similar to hardness of surfaces, the size of the squash court was seen as something to be respected, which potentially limited the amount of force players were willing to use. Participants also suggested that an outdoor version of these games would be appealing, " $a$ bit more of an open space" "I still want some mud, you do it in a field of mud, it'd be, it'd be perfect... Great fun."

\section{T2: Technology}

This theme describes technology used to implement the two games in our study. One of the key challenges in this work is understanding how to best integrate technology into intense physical gameplay without interrupting or overcomplicating the play experience. 86 of the total 771 units are described by this theme, which is divided into three category codes, Sound (24), Screen (25) and Exploring (37). Sound design was important in both games in communicating game state to players and in providing appropriate context for player actions. Participants enjoyed the digital game aesthetic created by the pumping music and game-related audio cues, "I thought it was cool because like, it sounds more like arcade.", which framed it very much as a game rather than a sporting activity, despite the squash court location. However, participants also commented that details communicated via audio instructions were often difficult to understand, "it's quite a like deep voice, so it's like lost, lost under some of the music," "quite hard to hear, also this room's quite echoey." Participants also suggested the addition of, "a visual cue, as well as the audio cue, just to like double up." Attention also appears to be an important factor, "you're sort of like not really paying attention to what it's saying, sort of paying attention to who you're meant to be attacking or defending yourself, you're worried too much that you're going to be the next one that's going to be attacked." The intention of 


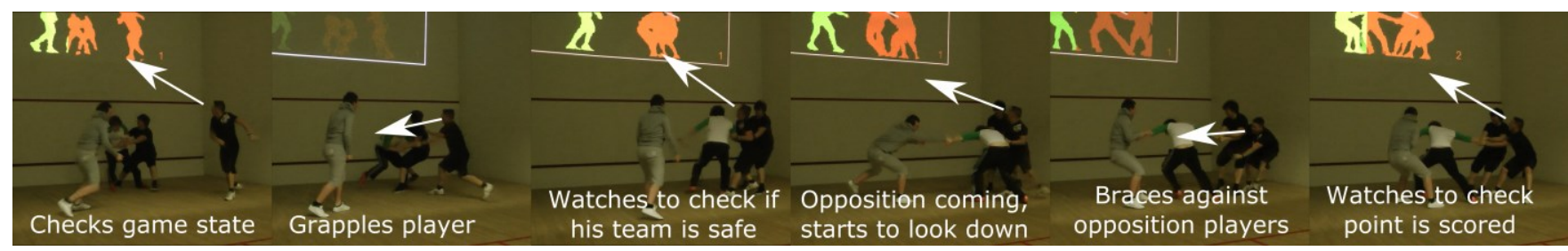

Figure 3. Arrow shows view direction over 6 seconds of BoP as the player switches between looking at screen and players.

these games was to encourage people to play physical games with each other, so the finding that players were too busy playing with each other to attend to the technology could be considered a success.

Participants discussed the role of the display in facilitating the BoP game. Some suggested that the screen was unnecessary in initial rounds. "It'd be better if you had lines on the floor, to tell you where you were." However, as the session wore on, participants increasingly found the display useful, "I wouldn't know who was kind of ... winning, unless I looked up." They described how they used the screen as part of game play, "it's like, you get yourself in a grappling position, have a quick look, to see if like, that grapple, will score you a point, then you, then you grapple harder" (see Figure 5). As this shows, whilst the key gameplay occurred on the floor, the display was key to creating the game of BoP and allowing players to be aware of the game state. While participants didn't initially find the display useful, as they became more familiar with game dynamics, they increasingly valued and used the display tactically.

Participants discussed exploratory learning they engaged in with the technology; instead of simply playing the games in the manner explained, participants were interested in how the technology enforced the rules. "I sort of realised that it, it worked on, errr, pixels, that's what's right isn't it, and so, so when you're sort of side on, you're er, less powerful than when you're face on, is that right," "my concern was, were we going to be too low, when we were on the ground, were we going to be too low for the camera to see. Were we too low?" At one point players in BoP used this to perform what Salen \& Zimmerman [25](p260) call 'workaround' cheating, where rather than grab the other team they tried to pose themselves to appear as large as possible to the camera (Figure 6). This exploratory learning also lead to some false beliefs, which in turn affected game play strategy, "obviously, because the green team were, automatically balanced towards them, we were, working harder, because

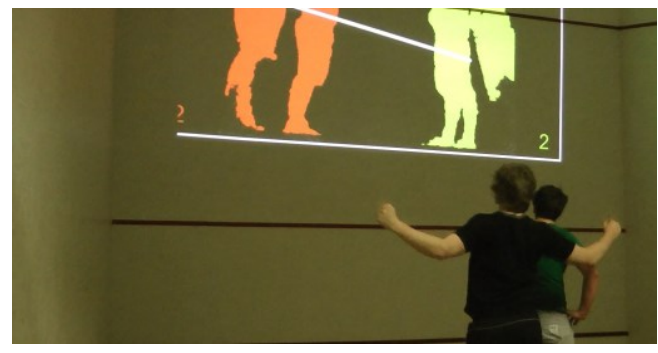

Figure 4. A player trying to make themselves as big as possible we, all they had to do is stay on their side, whereas we had to actually get them across to our side."

One key question we had was whether there was any point to making these games digital - we specifically asked participants whether they thought there were any advantages over similar non-digital games. They were positive about the way the computer system acts to make the state of play visible - "That sort of measurement [gesturing to show the bar in BoP], with the scale you can kind of see if you're winning and if you're losing so, if you're losing obviously you're going to change your strategy which you know, you're losing, if you're winning you're going to try and maintain your strategy, so I think having the visual display just makes it that much more, interactive and erm, I just know what's going on, if it's like the pushing and pulling game, you'd just be pushing and pulling, you'd lose sight of the objective really quickly, it's almost like a constant reminder, you know, of what you're aiming for as well". Both groups also mentioned that the games gave them an reason to play-fight, something enjoyable that they hadn't generally done since childhood "I guess when you're a bit more of an adult like, it's more acceptable when you're a kid, just run out into the field and people start tackling everyone, what you going to do, like you almost have instant rage and want to do it to someone, you can't, whereas this essentially gives you a bit of an opportunity, the confidence to do so, it's an excuse."

\section{T3: Game Design}

This theme describes participants discussion of issues related to the design of the three games examined in the study. 205 of a total 771 units are described by this theme, which is divided into six categories: Fun (29), Competition (21), Fairness (13), Other sports (39), Teamwork (28), Interacting with rules (36), and confusion (39). Throughout the sessions, participants mentioned on a number of occasions how they found the games fun, "was really good fun," "perfect... Great fun," "you could sell that, as like a day out experience." This was really important, since the games were intended to not only be difficult and physically challenging, but fun to take part in. One participant noted that part of that fun may have been derived from playing with good friends, and that playing with strangers, "it might be a little bit different, because you're tackling somebody you've got no like idea about", although given the colocated multiplayer nature of these games it is likely they would primarily be played with friends in any case. 
A common motivation for engaging in sport is a sense of competition [28](p64). Our participants certainly behaved competitively - "I think from a personal aspect, I think there is definitely a lot of pride, and you don't want to be the person who gets put on the ground," "winning. It's like even though if you didn't win the game, it's like, you know, it's just little victories throughout the game."

Related to competition, participants discussed the importance of fairness, or balance in ability between players, in driving the fun of the game. "It doesn't need to be like ridiculously fair, but it has to be fair enough," "it wasn't fair with us five," "if it was one team that gets beaten down, you're not want to, you're not going to keep playing are you?" This raises interesting questions for designers of brutal competitive games. For example, how can we design mechanics that don't consistently give advantage only to bigger and stronger players? Video game designers often create balance in multiplayer games through penalizing strong players and boosting weak players [4], but that strategy may not be appropriate in this environment. Indeed, one of the groups in our study incorrectly inferred that the technology was unfairly balanced against them and expressed disappointment, "because the green team were, automatically balanced towards them, we were, working harder" "I suppose it's kind of good, forcing one side to do something but yeah, it's maybe a bit unfair."

Participants frequently compared the challenge presented by the games with their experiences playing other sports, focusing most on rugby, "it's kind of the same as rugby, like "what can I do to get past," "I can understand why you wanted rugby players to do it. I think it'd be a bit... a bit of a different experience if you just had... lay people (?) for lack of a better word." Players also discussed how our games presented challenges that were different than rugby, "in rugby you're going for the ball whereas in this you're literally going for the person," "that bit is actually harder than rugby cause you get hit from all angles instead of normally just sort of like that, that direction <in front $>$." Thus, players existing experience in playing brutal games is clearly a resource that can be drawn upon in designing engaging brutal video games.

Participants in every interview session discussed tactics used in the previous game play session and speculated on the role of teamwork in succeeding. This was particularly evidenced in the discussion of $\mathrm{BoP}$, "teamwork is obviously really important like, if one of your team gets grabbed, you should grab your teammate and try and like pull him back, it's almost like, two people is better than one," "every time we saw someone like come across, we'd both try and jump on them," "focus on one person, get him down," "it literally takes your entire team effort to pull someone across." Participants also mentioned the importance of the social pressure in competitive team games in driving performance and endurance, "it's definitely what keeps me going in

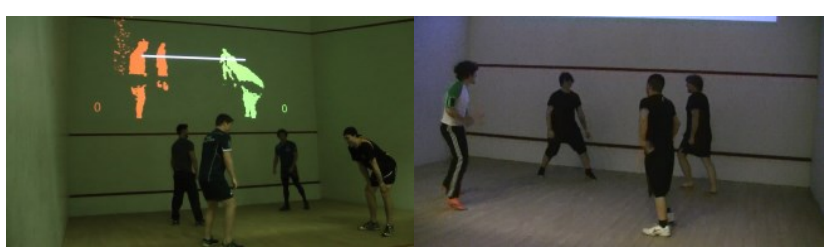

Figure 5. Self-organising at breaks in BoP and Bundle

sports, it's, if I know I've got a team kind of relying on me then I think 'well I can't stop'.,

Participants frequently discussed the rules of the games in the interview sessions. With BoP, there was appreciation for the breaks in game play that occurred every time a point was awarded, "when it starts again, you know it's a moment for you to stare at each other for a few seconds, while you're both thinking, like I literally <?> which would be the easier target," however players noted that such gaps, where they stopped and faced off (Figure 7) were essentially selforganised by the players rather than enforced by game rules, "we kind of naturally put gaps in, so, might be good to put them actually in the game." Indeed, the emergence of behavioural norms during play was fascinating to see, given that rules were a very light touch. This is emphasized by player reactions to one of the game rules that did interrupt players interaction with each other, "as soon as you grab them tight it goes switch sides, I'm like WHAT<flings hands down." It is interesting to note that design decisions intended to maintain player attention and spectator tension can actually break up the behavioural momentum of players, in a similar way to that of time-outs in competitive sports [11]. Given the highly physical nature of these games, timing and framing of breaks in play seems very important to the overall experience. With Bundle, players also discussed the breaks in game play as important to the overall experience, "the build-up is quite nice, because it takes quite a bit of time to decide who's on, so it kind of gives you time to kind of stand around and kind of think 'well what am I gonna do'." They also noted how the 3v1 nature of Bundle allowed for less intensive engagement activity than in the $2 \mathrm{v} 2$ game BoP, "that was kind of good because you get one turn at being the person at once, whereas the last time it was all the time."

There was a small amount of confusion over game play in BoP, "it maybe kind of gets lost, in like the, heat of the battle, what's being said, so like I, I wouldn't know who was kind of... winning, unless I looked up." However, there was far more confusion in Bundle, which relied only on audio instructions and feedback, "we heard people winning, although I had no idea why," "I still don't get what, how the scoring works," "it kept screaming my name." Participants made suggestions on how to improve the clarity of game play, "should have colours, instead of name," "if you had like a red shirt, green shirt, blue shirt, if it says 'red', you wouldn't have to be like oh, who's 'whatever name it is', you'd know." The use of team colours in organized sports suggests this may be a good strategy for brutal games. 


\section{T4: Physical Awareness}

One of the intentions of the project was to create play experiences that encouraged participants to attend to, reflect on and appreciate the physical qualities of their own bodies. This theme describes discussion related to participants' awareness and reflection on physical characteristics of their body. 174 of a total 771 units are described by this theme, which is divided into four categories: Fitness (58), Body Awareness (53), Injury (47), and Enjoyment of Pain (16).

The intention was to create games that are genuinely physically challenging, both in terms of strength and cardio vascular fitness. Most interview sessions began with players commenting on their own fitness, or the level of fitness required to play the games, "whoof. That takes it out of you doesn't it?" "absolutely knackered," "you actually, really feel like you're exercising," "massive like burst of loads of exercise, lot of fun." "The biggest problem I had with it is that I'm incredibly unfit, so, I got tired very quickly." Participants suggested that it was, "a really fun way of getting people fit," "you could bring our whole team in and do that for an hour, play the game, it's just a good way of keeping fit." Given the level of physical exertion required, the decision on how long game play sessions should be appears very important, "I thought the game length was good, because you still had, like, enough energy at the end of it to like keep going. But then like, yeah, maybe playing two in a row is a bit too much," "you wouldn't want to do any more rounds [after 3 rounds of BoP]," "if you have two people, keep swapping one out each time, so you only have two games at max." Comparisons were also drawn with commercial exergames, "like cardio really, you can feel it going in your chest, whereas with the Wii stuff you don't really get to that level of tired." This demonstrates that computer technology can be used in ways that encourage genuinely high intensity exercise (unlike the relatively low levels of intensity found in most exertion games [31]).

Participants discussed how the games encouraged them to perceive and reflect on the physicality of their own bodies, "if you've got a cut face or something you enjoy it, that's part of, even if you've lost, you know, you still, you've not backed out," "it was just instinct, you think what can I use my strength for here" "when I was playing it, I was sort of more concerned with just sort of wrestling a bit you know," "I do love the aggressive side, and this, this kind of nice feeling, almost a primitive feeling." It seems that the enjoyment of brute force games comes from the rare opportunity to feel and use your own strength.

Participants also discussed the potential of these games to cause physical injury, and the bumps and bruises that they got through playing, "the walls didn't bother us... might bother some people," "I hit the wall, errr, it was fine, then, I dunno, I, I play squash so, kind of know what it feels like I guess," "the worst we got is like scuffed knees and stuff, so it can't be too bad." One player did have to sit down for a few minutes due to a knee injury, "It was alright, I think it was just my own, not stretching enough at the beginning, you know." Overall, despite their brutal nature, it seems that the games didn't pose undue risk of serious injury. One participant suggested that BoP presented less risk of injury than Bundle, "because you're trying to like avoid, you don't want to be on the other team's side, you're not just going for each other, whereas this, just literally it's to stop someone, you're just going for it, like < Player > got like tackled down to ground."

Indeed, it was suggested that suffering physical pain is part of the enjoyment of playing brutal games like rugby and martial arts, "if you've been hurt, you enjoy having war wounds," "if you're hurt, still like, if you've got a cut face or something you enjoy it, that's part of, even if you've lost, you know, you still, you've not backed out," "in football, someone would fall over and they would cry for half an hour, and all that crap, whereas rugby like, you know you're going to get hurt, so you kind of go into it, and if you do get hurt, everyone's like 'sorry'<shrugging $>$, there's no hard feelings, it's similar to this like."

\section{T5: Brutal Play}

T4 "Physical awareness" describes participant's discussion of how our games provoked reflection over the physical nature of their bodies. T3 discussed the specific design choices made in our games. A separate theme emerged from discussion of brutal play more generally as a form of play and source of enjoyment. 60 of a total 771 units are described by this theme, divided into three categories: Violence / aggression (44), domination (10), self-restraint (6).

Participants discussed how they viewed violence and aggression as playful and enjoyable, "I do love the aggressive side, and this, this kind of nice feeling, almost a primitive feeling," "I enjoyed the throwing people," "It's mauling really, it's... it's classic playfighting," "me and my friend, we like wrestled each other because we felt like it." Interestingly, one participant mentioned how violent games allow people to play in a similar way to children, "its more acceptable when you're a kid, just run out into the field and people start tackling everyone... this essentially gives you a bit of an opportunity, the confidence to do so, it's an excuse." However, participants disagreed with our description of the games as violent, "I wouldn't describe it as violence... it's like a test of strength ...... violence is more you intend to hurt people." 


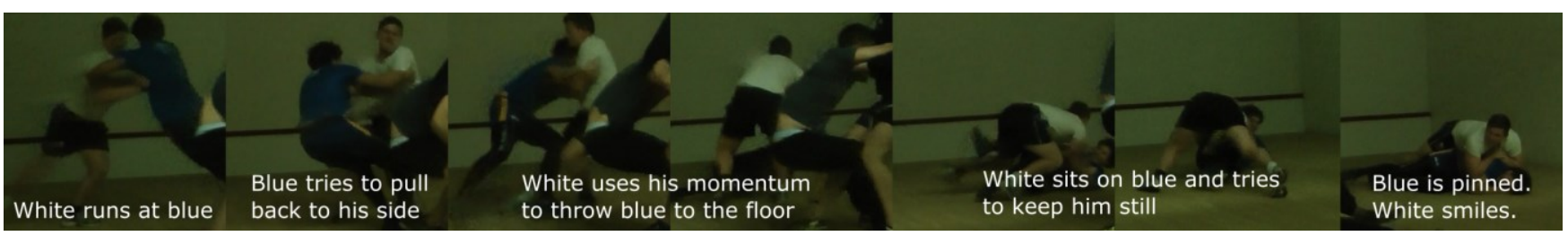

Figure 6. White player dominates blue, throwing him to the ground and sitting on him (and shows his enjoyment with a big smile)

Participants suggested that a lot of the enjoyment of brutal games comes from the opportunity to physically dominate other players (see e.g. Figure 8). "Knowing that, that you're stronger than someone else if you sort of hit in attack or if you run through them there's a sense of like 'oh cool'," "you don't want to be the person who gets put on the ground, so, yeah, the person who puts people on the ground," "even though if you didn't win the game, it's like, you know, it's just little victories throughout the game, it's like, you know, you actually manage to like tackle someone, get them down, it's like 'yes, I'm stronger, I have the better technique." Our interviews suggest that the enjoyment of brute force games comes not only from the rare opportunity to feel and use your own strength, but also from a sense of competition and opportunity to dominate other players physically.

Of course the counterintuitive, but entirely necessary, feature of all brutal games is that although game play involves physical aggression directed at other people there is a great deal of respect and self-restraint required so that people don't get unnecessarily injured, "you don't want to get hurt yourself, you don't want to hurt them," "you've got a kind of mutual respect for people like, you think 'I could throw him to the ground, but when I'm on, they'll thrown me," "We're having a good go at each other, but you didn't see me like smash <player>'s head into the wall or anything, that may be a bit too violent". Figure 9 shows a moment of self-restraint in Bundle, where players were lifting the "it" player, but his head dropped towards the floor, and the players stopped to check he was uninjured.

\section{DISCUSSION - STRATEGIES FOR DESIGNING BRUTAL MULTIPLAYER GAMES}

Mueller et al., [16] identified seven identifying features of full contact non-digital sports; competitiveness, intensity, directness, injuries, social aspect, fearlessness, spectatorship and organizational. Our goal was to build digital games that encouraged qualitatively similar player behaviour, and through doing this, to understand specific opportunities and challenges facing designers of brutal video games. Our study participants demonstrated many instances of each of Muellers components. For example, discussion of competition and injuries were evident in our

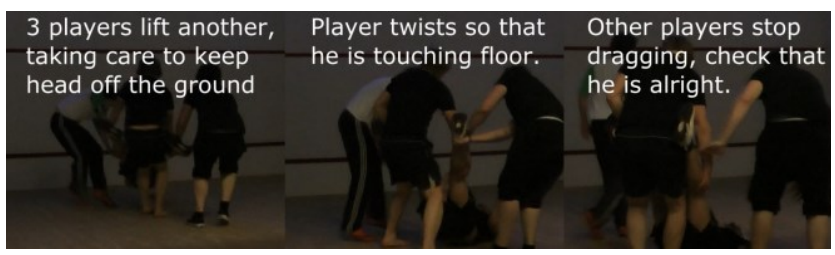

Figure 7. Player at risk, other players stop to check he is okay study. Directness, intensity and social aspect were seen in discussions of violence laggression, body and teamwork.

Mueller's categories were identified initially from an online survey and were found useful in analysing games that aimed to minimize inter-player contact. Our work was more specifically interested in understanding the experience of players of digital brutal games. Thus, our findings identify more specific considerations for digital brutal game design; summarized as space, technology, game design, physical awareness and brutal play. In the following section we present a set of design strategies based on the reported experience of our players, our experience as designers and the literature on brutal game play. We reference this discussion back to each of the identified themes.

\section{Design loose and negotiable rules}

A core concern in brutal game design is in how finely to specify 1) rules that govern allowed movements and 2) winning conditions. Computer-based fighting games (i.e., Street Fighter) traditionally allow only a very constrained set of movements. In contrast, children's physical games typically have loose and negotiable rules and winning conditions [3]. Contact sports such as rugby and mixed martial arts [21] have well specified winning conditions, but allow freedom to players in using the movement of their bodies in creative ways to achieve those conditions. Our experience suggests that this is also a good model for brutal video games. In our games, we sense pixel positions on a camera (BoP) or whole body movement (Bundle), things which are affected by brute force actions but in no way specify particular actions. This allowed players to use their imagination and perform a wide range of moves that were not envisioned by us (T5: Brutal Play). It also gave them space to exercise self-restraint (T5), to negotiate appropriate levels of force, to draw on their previous experience and expertise with traditional contact sports (T3: Game Design), and to self-organise how they choose to play the game (T3).

Tune attentional demands of system to those of physical interaction

One key challenge in this work is in understanding how to integrate technology into intense physical gameplay without interrupting or overcomplicating play experiences. Players of brutal games must attend closely to their own bodily sensations and to body positioning and movements of other players (T4: Physical awareness), which is necessary for competitive advantage and safety. Requiring players to redirect their visual attention to a screen to receive gamecritical information is problematic (T2: Technology). We attempted to overcome this issue in two ways. Firstly loud 
audio cues were intended to reduce the need to look at the screen, and secondly in BoP, the screen was designed to be simple and easy to understand with a single glance (T2). Bundle's audio only design was less successful; Players struggled to hear and understand audio whilst playing, pausing and interrupting play to do so, and there was no visual back-up if information was missed. It seems that a combination of audio and visual may be most useful, with audio designed to be comprehensible so as to avoid interrupting players' in-game concentration, and video being designed to give an always visible summary of game state easily taken in in a brief glance. We may also take inspiration from wider HCI work on split attention while performing complex physical movements such as cycling $[14,24]$. For example we could utilise space to make displays where people may be looking by projecting information on floor or multiple walls [6] (T1:Space).

\section{Create Breaks in Play and Short Games}

Playing brute force games can involve massive aerobic and anaerobic exertion (T4: Physical Awareness). This means that players require frequent breaks in play. We found that 3 minute long rounds of BoP or Bundle were at the edge of what players could handle. Furthermore, within rounds, after each point had been scored there was a brief pause to allow players to recover. These were necessary from a physical exertion point of view, but we also found that enforced pauses in play added a level of suspense and tactical decision making to the game (T3: Game Design). It is also important to limit how many games players can play in one session, as even our fit and sporty players were exhausted after a 5 game session. One way to support regular breaks, could be to have an 'action replay' on the screen in between phases of play, that shows a replay of the previous bout. This would give time for players to rest and also an opportunity to see what happened, how their relative positions and tactics affected gameplay, and to learn.

Consider how the Play Space Modulates Physical Force Physical characteristics of play environments (size of room, hardness of surfaces) will influence player comfort with engaging in brute force play, or the level of force they will be comfortable with. Our squash court play space had hard walls and floors. The hard space meant players who hit the walls or went down hard got bruised (T1: Space, T4: Physical Awareness). However, players also felt that the hard space modulated how physical they were willing to be in their play (T5: Brutal Play); a more padded play space, whilst it may have reduced minor injuries caused by the environment, may also have increased potential for injuries directly caused by other players. The relatively constrained space of a squash court also limits speed and momentum players can achieve, and means that players are always close, so it remains a physical contact game rather than drifting into chasing and running away (T3: Game Design).

\section{Design for Balance}

Enjoyment of brute force games comes not only from the rare opportunity to feel and use your own strength, but also from a sense of competition and opportunity to dominate other players physically. However, this experience is only enjoyable if there is a sense of fairness and balance (T3: Game design). One of the biggest challenges in this domain is in designing mechanics that don't consistently give advantage to bigger and stronger players. Video game designers often create balance in multiplayer games through penalizing strong players and boosting weak players [4], and in non-contact exertion games by modulating effort required based on player fitness [20]. That strategy seems less feasible in brutal games, where there is no obvious way to handicap players. A more productive approach may be to learn from how sports deal with differing abilities, for example, the designs of American football and rugby require contributions from players of different body types and skills working together, and mixed martial arts, due to its open-ended rules, allows for much bigger physical variation in opposing players than traditional boxing.

\section{Trust Players' Self Restraint}

Where play involves brute force physical aggression directed at other people, a great deal of respect and selfrestraint is required so that people don't get unnecessarily injured (T5: Brutal Play) [7]. Whilst we may wish to include some limits on physicality in games, a computer can only do so much to enforce limits. Designers must trust players to 'play nicely' and negotiate between each other what level of physicality they are comfortable with.

\section{Consider if Safety Cover is Appropriate}

Whilst players will exercise self-restraint, clearly physical games can end in injuries. We chose a test location which had first aid cover for this study; we would suggest that this is appropriate at least for play-testing, until it is clear how violent players are likely to be in a game and while design changes are being made which may modulate levels of player violence. It is possible that some games may involve a level of risk such that first aid cover is always appropriate, as is the case for most non-digital contact sports.

\section{CONCLUSION}

Non-digital games that involve full force contact between players, such as Boxing, Mixed Martial Arts and Rugby are hugely popular across the world. However, digital games rarely encourage a similar type of inter-player contact. We designed and studied two digital full-contact games. Findings suggested five key components of the brutal play experience in our games, and informed a set of considerations for designing digital brutal play experiences. We hope that this work can open up a new and exciting space for the design of engaging game experiences based on awareness and enjoyment of our own and others' physicality and capacity for brute force aggression.

\section{ACKNOWLEDGEMENTS}

Joe Marshall is funded by Leverhulme Trust (ECF/2012677). This work was supported by the AHRC Performance and Games network (Ref AH/L009080/1). 


\section{REFERENCES}

1. Naomi Alderman. 2012. Zombies, Run!

2. Virginia Braun and Victoria Clarke. 2008. Using thematic analysis in psychology. Qualitative Research in Psychology. Retrieved September 1, 2015 from http://www.tandfonline.com/doi/abs/10.1191/14780887 06qp063oa\#.VeYvgPlVhBc

3. Andrew Burn. 2013. Computer games on the playground : Ludic systems, dramatized narrative and virtual embodiment. In Children, Media And Playground Cultures. Palgrave Macmillan.

4. Jared E. Cechanowicz, Carl Gutwin, Scott Bateman, Regan Mandryk, and Ian Stavness. 2014. Improving player balancing in racing games. Proceedings of the first ACM SIGCHI annual symposium on Computerhuman interaction in play - CHI PLAY'14, ACM Press, 47-56. http://doi.org/10.1145/2658537.2658701

5. Woohyeok Choi, Jeungmin Oh, Taiwoo Park, et al. 2014. MobyDick. Proceedings of the 12th ACM Conference on Embedded Network Sensor Systems SenSys '14, ACM Press, 76-90. http://doi.org/10.1145/2668332.2668352

6. Alexandru Dancu, Zlatko Franjcic, and Morten Fjeld. 2014. Smart flashlight. Proceedings of the 32nd annual ACM conference on Human factors in computing systems - CHI '14, ACM Press, 3627-3630. http://doi.org/10.1145/2556288.2557289

7. Larry de Garis. 2010. Sometimes a bloody nose is just a bloody nose: play and contest in boxing, wrestling, and ethnography. Sport in Society 13, 6, 935-951. http://doi.org/10.1080/17430437.2010.491264

8. P David Howe. 2001. Women's Rugby and the Nexus Between Embodiment, Professionalism and Sexuality: An Ethnographic Account. Football Studies 4, 2, 7792.

9. K Isbister and FF Mueller. 2014. Guidelines for the Design of Movement-Based Games and Their Relevance to HCI. Human-Computer Interaction. Retrieved January 21, 2015 from http://www.tandfonline.com/doi/abs/10.1080/07370024 .2014 .996647

10. Ivo Jirásek and Emanuel Hurych. 2012. Pain and Suffering in Sport. Human Movement 13, 2, 185-189. Retrieved August 27, 2013 from http://www.degruyter.com/view/j/humo.2012.13.issue2/v10038-012-0021-6/v10038-012-0021-6.xml

11. F Charles Mace and Joseph S Lalli. 1992. Behavioral momentum in college basketball. Journal of applied behavior analysis 25, 3, 657-63. Retrieved September 4, 2015 from http://www.pubmedcentral.nih.gov/articlerender.fcgi?a rtid $=1279747 \&$ tool $=$ pmcentrez\&rendertype $=$ abstract
12. Elena Márquez Segura, Annika Waern, Jin Moen, and Carolina Johansson. 2013. The design space of body games. Proceedings of the SIGCHI Conference on Human Factors in Computing Systems - CHI '13, ACM Press, 3365. http://doi.org/10.1145/2470654.2466461

13. Joe Marshall, Frank Loesche, Conor Linehan, Daniel Johnson, and Bruno Martelli. 2015. Grand Push Auto: A Car-based exertion game. Ext. Abstracts CHI Play.

14. Joe Marshall and Paul Tennent. 2013. Mobile interaction does not exist. CHI' 13 Extended Abstracts on Human Factors in Computing Systems on - CHI EA '13, ACM Press, 2069. http://doi.org/10.1145/2468356.2468725

15. Greta Mitchell and Andy Clarke. 2011. Game catcher: playing, recording and archiving playground games. In Museums at play: games, interaction and learning. Museums Etc., 426-439.

16. Florian "Floyd" Mueller, Stefan Agamanolis, Frank Vetere, and Martin Gibbs. 2009. Brute force interactions. Proceedings of the 21st Annual Conference of the Australian Computer-Human Interaction Special Interest Group on Design: Open 24/7 - OZCHI '09, ACM Press, 57. http://doi.org/10.1145/1738826.1738836

17. Florian "Floyd" Mueller, Martin Gibbs, Frank Vetere, Stefan Agamanolis, and Darren Edge. 2014. Designing mediated combat play. Proceedings of the 8 th International Conference on Tangible, Embedded and Embodied Interaction - TEI '14, ACM Press, 149-156. http://doi.org/10.1145/2540930.2540937

18. Florian Mueller, Shannon O'Brien, and Alex Thorogood. 2007. Jogging over a distance. CHI '07 extended abstracts on Human factors in computing systems - CHI '07, ACM Press, 1989. http://doi.org/10.1145/1240866.1240937

19. Florian Mueller, Cagdas Toprak, Eberhard Graether, Wouter Walmink, Bert Bongers, and Elise van den Hoven. 2012. Hanging off a bar. Proceedings of the 2012 ACM annual conference extended abstracts on Human Factors in Computing Systems Extended Abstracts - CHI EA '12, ACM Press, 1055. http://doi.org/10.1145/2212776.2212384

20. Florian Mueller, Frank Vetere, Martin Gibbs, et al. 2012. Balancing exertion experiences. Proceedings of the 2012 ACM annual conference on Human Factors in Computing Systems - CHI '12, ACM Press, 1853. http://doi.org/10.1145/2207676.2208322

21. John Paul. 2015. Sport and Bodily Empowerment: Female Athletes' Experiences with Roller Derby, Mixed Martial Arts, and Rugby. Journal of Alternative Perspectives in the Social Sciences 6, 4, 402-438. 
22. A D Pellegrini and P K Smith. 1998. Physical activity play: the nature and function of a neglected aspect of playing. Child development 69, 3, 577-98. Retrieved September 1, 2015 from http://www.ncbi.nlm.nih.gov/pubmed/9680672

23. Steve Roud. 2010. The Lore of the Playground: One hundred years of children's games, rhymes and traditions. Random House Books.

24. Duncan Rowland, Martin Flintham, Leif Oppermann, et al. 2009. Ubikequitous Computing: Designing Interactive Experiences for Cyclists. Proceedings of Mobile HCI '09, ACM. http://doi.org/10.1145/1613858.1613886

25. Katie Salen and Eric Zimmerman. 2004. Rules of Play: Game Design Fundamentals. MIT Press. Retrieved September 2, 2015 from https://books.google.com/books?id=UMxyczrZuQC\&pgis $=1$

26. Michael D. Smith. 1975. The Legitimation of violence. Canadian Review of Sociology and Anthropology 12, 1.

27. Amanda L Snyder, Cay Anderson-Hanley, and Paul J Arciero. 2012. Virtual and live social facilitation while exergaming: competitiveness moderates exercise intensity. Journal of sport \& exercise psychology 34, 2, 252-9. Retrieved September 16, 2013 from http://www.ncbi.nlm.nih.gov/pubmed/22605365

28. Gershon Tenenbaum and Robert C. Eklund (eds.). 2007. Handbook of Sport Psychology. John Wiley \& Sons. Retrieved September 4, 2015 from
29. https://books.google.co.uk/books/about/Handbook_of_ Sport_Psychology.html?id=h2m7196ZStgC\&pgis $=1$

30. Steffen P. Walz and Sebastian Deterding (eds.). 2015. The Gameful World: Approaches, Issues, Applications. MIT Press.

31. Marc D. Weinstein, Michael D. Smith, and David L. Wiesenthal. 1995. Masculinity and hockey violence. Sex Roles 33, 11-12, 831-847. http://doi.org/10.1007/BF01544782

32. Anthony Whitehead, Hannah Johnston, Nicole Nixon, and Jo Welch. 2010. Exergame effectiveness.

Proceedings of the 5th ACM SIGGRAPH Symposium on Video Games - Sandbox '10, ACM Press, 55-62. http://doi.org/10.1145/1836135.1836144

33. Douglas Wilson. 2011. Brutally Unfair Tactics Totally OK Now: On Self-Effacing Games and

Unachievements. Game Studies 11, 1. Retrieved October 22, 2012 from http://gamestudies.org/1101/articles/wilson

34. Douglas Wilson. 2012. Designing for the Pleasures of Disputation - or - How to make friends by trying to kick them ! Retrieved from http://doougle.net/phd/Designing_for_the_Pleasures_of Disputation.pdf

35. World Squash Federation. 2012. Court Specifications. Retrieved July 21, 2015 from http://www.worldsquash.org/ws/resources/courtconstruction 